This is an electronic reprint of the original article. This reprint may differ from the original in pagination and typographic detail.

Author(s): Äystö, Juha

Title: $\quad$ A New Book on Isotope Discoveries by Michael Thoennessen

Year: $\quad 2017$

Version:

Please cite the original version:

Äystö, J. (2017). A New Book on Isotope Discoveries by Michael Thoennessen.

Nuclear Physics News, 27(1), 40. https://doi.org/10.1080/10619127.2017.1280367

All material supplied via JYX is protected by copyright and other intellectual property rights, and duplication or sale of all or part of any of the repository collections is not permitted, except that material may be duplicated by you for your research use or educational purposes in electronic or print form. You must obtain permission for any other use. Electronic or print copies may not be offered, whether for sale or otherwise to anyone who is not an authorised user. 


\section{A new book on the Isotope discoveries by Michael Thoennessen}

A new Springer book "The Discovery of Isotopes - A complete compilation" by Michael Thoennessen represents an incredible amount of effort to unravel and organize the published information of an important part of nuclear physics and its history. In over 400 pages the book presents the discovery experiments of 3211 isotopes of 118 elements. It covers the time period from the early days of nuclear physics up to the end of 2015. The book composes of 17 chapters and includes altogether 1551 references to original works. In addition as a separate section, it includes a comprehensive and detailed list of isotopes discovered together with information on the laboratory, the reference to the original article and the first author of the article.

With the help of his undergraduate students, Thoennessen has compiled and published most of the information of the book first in the Journal Atomic Data and Nuclear Data Tables. Using these series of papers, instead of following the order of isotope chains for each proton number, the text part of the book has been organized on a different approach. It starts first from historical description of the early research on isotopes and related discoveries in nuclear physics until the second world war and then continues more in the order based on the reaction mechanisms and detection methods used in the discoveries.

The book presents a nicely ordered description and related original references of the early days of the isotope research as part of the history of nuclear physics. The definition of the concept of isotope was first introduced by Soddy (1913) who originally drew attention to the existence of isotopes or "nuclides with similar chemical behavior," in the radioactive series. It is remarkable, that only in 1932, following the discovery of neutron by Chadwick, the concept of isotope finally reached its full understanding. This was then followed by a series of discoveries of artificial radioactive isotopes starting by experiments of Jolie and Curie in 1934. Since then the field developed in a straightforward way, largely due to various ingenious developments in accelerators and associated research techniques. The number of discovered new isotopes per year reached its maximum in early 1950 s and 1970 s followed by a more regular number of about 20 per year until these days. High-energy nuclear fragmentation is now the dominating reaction mechanism coupled with large spectrometers and has been covered by the leading facilities at GSI, GANIL, NSCL and RIKEN, to be followed by the FRIB and Super-FRS of FAIR which are under construction in the US and Germany, respectively.

As a whole this book presents a carefully written piece of literature and deserves a place in the book shelf of a nuclear physicist. It is written with a good style with very few typos in it. It offers a useful source of information also for students, teachers, as well as to non-experts. It is highly recommended reading as a support material for nuclear physics classes in high school and universities.

For continuous update of the Discovery of Nuclides Project, see https://people.nscl.msu.edu/ thoennes/isotopes/ 